\title{
LATERAL GROWTH AFFECTS XYLEM MATURATION PROPERTIES OF 8-YEAR-OLD BIG-LEAF MAHOGANY (SWIETENIA MACROPHYLLA)
}

\author{
Gilbero DM"1, 3, *, Abasolo WP2, Matsuo $\mathrm{M}^{3}$ \& Yamamoto $\mathrm{H}^{3}$ \\ ${ }^{1}$ Forest and Wetland Research, Development and Extension Center, Ecosystem Research and Development Bureau of \\ Department of Environment and Natural Resources, Bislig City, 8311, Philippines \\ ${ }^{2}$ College of Forestry and Natural Resources, University of the Philippines-Los Baños, Laguna, 4030, Philippines \\ ${ }^{3}$ Laboratory of Wood Physics, Graduate School of Bio-agricultural Sciences, Nagoya University, Furo-Cho, Chikusa, \\ 464-8601 Nagoya, Japan \\ *forgilbero@gmail.com
}

Submitted September 2019; accepted May 2021

\begin{abstract}
The area of juvenile wood zone of an 8-year-old planted big-leaf mahogany (Swietenia macrophylla) was uniform regardless of diameter. Hence, it was assumed that xylem maturation is dependent on diameter. Radial distribution patterns with reference from the pith exhibited short fibre and vessel lengths, narrow vessel width and low xylem density, and exhibited gradual increase outward and became more or less stable near the bark. However, the radial distribution patterns of fibre width and modulus of elasticity were scattered regardless of tree diameter sizes. Fibre length, vessel length, vessel width and xylem density of the juvenile wood zones showed significant differences compared with the transition and mature wood zones. However, no significant difference was observed between transition wood zone and mature wood zone except for fibre length. A negative correlation was observed in fibre length, vessel length, vessel width and xylem density in terms of their relationship with diameter at breast height and the radial distribution of fibre (i.e. b-value), and the diameter boundaries of the three wood zones. At diameters 18.08, 17.36, 16.23 and $17.87 \mathrm{~cm}$ respectively, fibre length, vessel length, vessel width and xylem density can be used to identify xylem maturation boundary.
\end{abstract}

Keywords: Radial distribution pattern, b-value, diameter boundaries, fibre length, vessel length, vessel width

\section{INTRODUCTION}

The growing demand for forest products such as timber becomes a worldwide challenge on how to balance forest regulations in response to environmental concerns and utilisation of timber resources. Sustainable tree plantations of fast-growing species are the best option to meet the increasing demand for timber. However, planting of fast growing trees causes an issue in the utilisation of juvenile wood.

Some small-scale tree farmers are encouraged to bargain early-age planted trees because of high demand and price. The younger age plantation usually contains timber with large proportion of developing juvenile wood. Wood near the pith of a tree, i.e. juvenile wood, is different from wood near the bark, i.e. mature wood (Maeglin 1987). The presence of juvenile wood can reduce mechanical properties as well as cause warping, excessive shrinking and swelling, fuzzy grain, and general instability in the manufacture and use of the wood. These problems may show up in the wood when sawing, veneering, drying and machining.

Wood maturity is one of the important factors to consider in terms of stability of wood properties when used as raw materials for building and furniture. It is very important to know whether maturation properties are dependent on cambium age or tree diameter. Having knowledge on the significant features of wood maturation is important to the silvicultural management of tree plantations.

The use of fibre length to examine xylem maturation property, which may depend on either cambium age or diameter of a tree has 
been studied in different hardwood species (Honjo et al. 2005, Huang \& Furukawa 2000, Kojima et al. 2009). In the case of Japanese red pine (Pinus densiflora), xylem maturation depends on cambium age (Sudo 1973). Several studies have been carried out on the structural changes during transition from juvenile to adult wood in conifers (Bendtsen 1978, Shiokura 1982, Lee \& Wang 1996). This means that the faster a specimen grows at the early growing stage, the higher is the diameter of juvenile wood when it is harvested. In hardwood, e.g. in Acacia spp. and Paraserianthes spp., radial variation of fibre length was related to growth rate rather than age of cambium; thus, xylem maturation was dependent on diameter growth (Honjo et al. (2005). In Eucalyptus spp., xylem maturation was controlled by cambium age (Kojima et al. 2009). Fibre length and microfibril angle are the best anatomical indicators in delineating the demarcation point between juvenile and mature wood (Rahayu et al. 2014).

In this study we investigated the radial distribution of growth strain and xylem maturation properties of an 8-year-old planted big-leaf mahogany. This study determined the effects of lateral growth on the xylem maturation properties. These progeny field trial sites are crucial in supporting tree improvement programme in the country. The field trial comprises 73 individual families of best performing mother trees of big-leaf mahogany from different tree plantations and reforestation projects throughout the Philippines. The selected progenies were planted at two sites (Butuan City and Cagayan de Oro City in Mindanao, Philippines) with distinct growing conditions. The progeny field trial measured and assessed the phenotypic growth performance of progenies as an expression of combining factors of genetic and environment. Since, the optimum goal of this work was to produce quality raw material as timber, it was deemed important to study the wood properties of this tree species as a progress to tree improvement programme of the country.

\section{MATERIALS AND METHODS}

\section{Study area and sample trial sites}

Experimental samples were randomly selected from two established progeny field trial sites of big-leaf mahogany located in Butuan City and Cagayan de Oro City, which represent contrasting growing conditions within the target plantation region in Northern Mindanao, Philippines (Figure 1, Table 1). The trial sites were established in September of 2009 by the Department of Environment and Natural Resources, Philippines with support

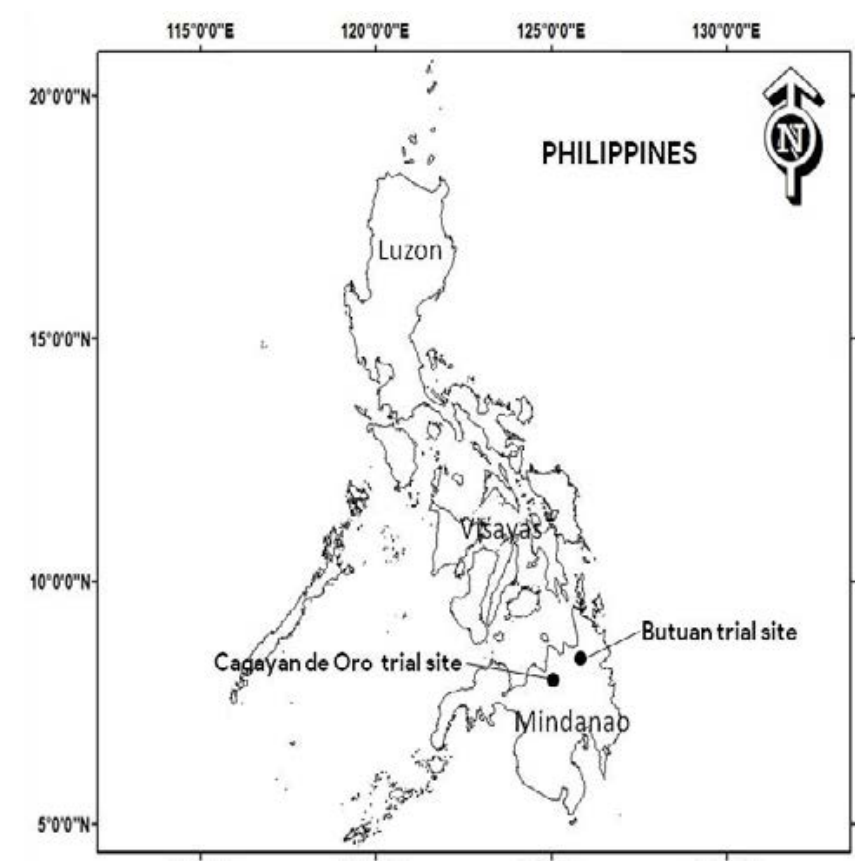

Figure 1 Locations $(\bullet)$ of the two trial sites of big-leaf mahogany (Sweitenia macrophylla) in the Philippines 
Table 1 Location and description of sampling sites

\begin{tabular}{|c|c|c|c|c|c|c|c|c|}
\hline \multirow[t]{2}{*}{ Trial site } & \multicolumn{2}{|c|}{ Location } & \multirow{2}{*}{$\begin{array}{c}\text { Elevation } \\
(\mathrm{m} \text { asl })\end{array}$} & \multirow{2}{*}{$\begin{array}{c}\text { Annual rainfall } \\
(\mathrm{mm})\end{array}$} & \multicolumn{4}{|c|}{ Soil } \\
\hline & Latitude & Longitude & & & $\mathrm{pH}$ & $\begin{array}{c}\text { Organic } \\
\text { matter }(\%)\end{array}$ & $\begin{array}{l}\text { Phosphorus } \\
\text { (ppm) }\end{array}$ & $\begin{array}{l}\text { Potassium } \\
(\mathrm{ppm})\end{array}$ \\
\hline Butuan & $8^{\circ} 56^{\prime} \mathrm{N}$ & $125^{\circ} 35^{\prime} \mathrm{E}$ & $13-15$ & 2057 & 6.8 & 1.2 & 4.5 & 144 \\
\hline Cagayan de Oro & $8^{\circ} 23^{\prime} \mathrm{N}$ & $124^{\circ} 42^{\prime} \mathrm{E}$ & $413-415$ & 1703 & 5.8 & 4.5 & 1.3 & 48 \\
\hline
\end{tabular}

Abarquez et al. (2015)

from the Commonwealth Scientific and Industrial Research Organization, Australia and the Australian Government (AusAID Public Sector Linkages Program) (Abarquez et al. 2015).

\section{Plant material}

Twelve tree samples (six trees from each site) of different diameter classes were randomly selected from the 8-year-old progeny trial sites. Table 2 show the average lateral growth data (diameter at breast height, $\mathrm{DBH}$ ) of tree samples in different diameter classes.

\section{Radial distribution pattern}

In every trial site, there were 12 test trees or 4 trees per diameter class (large, medium and small) that were used in the study. From the $\mathrm{DBH}$, a quarter-sawn board measuring $5 \mathrm{~cm}$ thick and length that was $2.5 \times$ the $\mathrm{DBH}$, were prepared from the pith to the north and the south sides of the stem, excluding the bark. Sampling points were set at every $2 \mathrm{~cm}$ from the pith to the bark portion at the midspan of the board length (Figure 2). Wood samples from the sampling points were prepared for the measurements of fibre length and width,

Table 2 Average lateral growth data (diameter at breast height (DBH) and standard deviation) of big-leaf mahogany samples in different diameter classes

\begin{tabular}{lccc}
\hline Diameter class & \multicolumn{2}{c}{ No. of test trees } & Average DBH (SD) cm \\
\cline { 2 - 3 } & Butuan & Cagayan de Oro & \\
\hline Large & 2 & 2 & $22.88(1.75)$ \\
Medium & 2 & 2 & $18.30(0.89)$ \\
Small & 2 & 2 & $14.18(0.39)$ \\
Total & 6 & 6 & \\
\hline
\end{tabular}

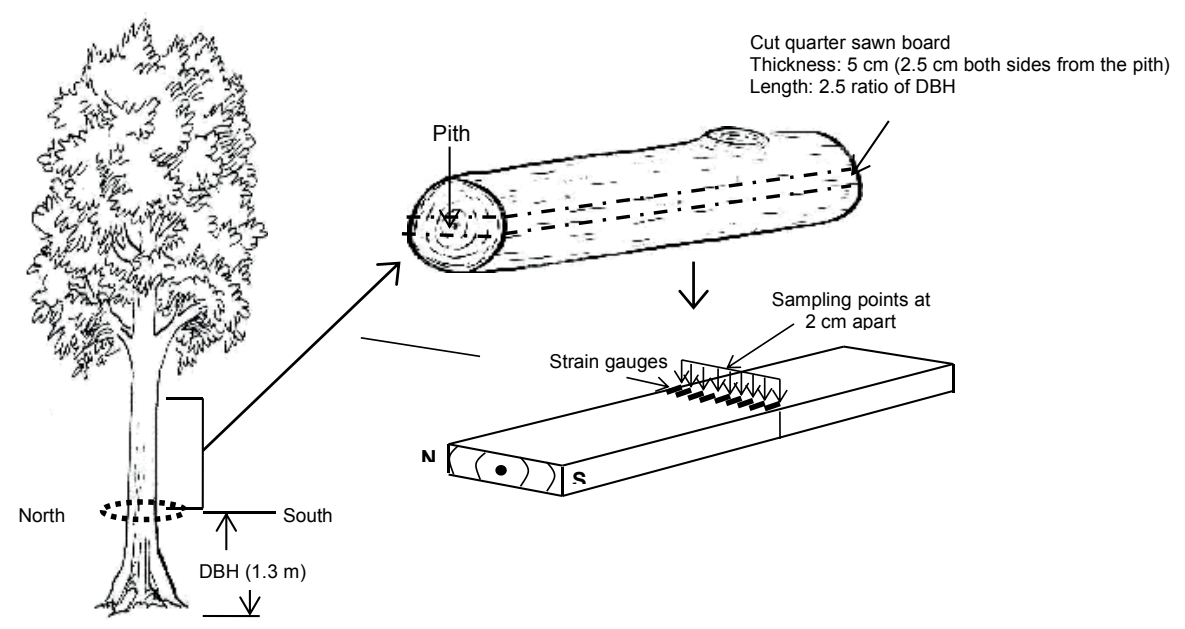

Figure 2 Sampling points of radial distribution patterns from the pith to north and south side of quarter sawn board with 2-cm intervals located at the center (length is $2.5 \times$ the $\mathrm{DBH}$ ) 
vessel length and width, xylem density, and modulus of elasticity (MOE).

\section{Xylem density}

Wood samples $(1 \mathrm{~cm} \times 1 \mathrm{~cm} \times 1 \mathrm{~cm})$ were prepared and measured from the rectangular specimen taken from every interval of $2 \mathrm{~cm}$ from the pith to the bark. These samples were seasoned at room temperature inside a desiccator containing saturated aqueous solution of $\mathrm{NaCl}$ for 1 week until equilibrium was met in order to achieve air dried state. Density was determined using mercury displacement method (Kollmann \& Cote 1968, Kojima et al. 2009).

\section{Fibre length, fibre width, vessel length} and vessel width

After the measurement of xylem density, part of each cubic specimen was treated in a compound liquid of water, potassium chlorate and $60 \%$ nitric acid (Saiki et al. 1989), followed by $10 \% \mathrm{NaOH}$ (aq) and then defiberised (Cheng et al. 2000) and dispersed in an aqueous suspension. A drop of defiberised wood suspension was placed on a glass slide and then covered with cover slip. At least 90 whole fibres were randomly selected and pictures of all the vessel elements in every wood block specimen were captured using digital microscope. The captured images of fibre and vessel elements were processed using image processor software (Image $\mathrm{J}$ ) in order to measure the fibre length, fibre width, vessel length and vessel width.

\section{Modulus of elasticity}

Segmented wood sample specimen $(0.5 \mathrm{~cm}$ $(\mathrm{R}) \times 1 \mathrm{~cm}(\mathrm{~T}) \times 10 \mathrm{~cm}(\mathrm{~L}))$ were taken at $1-\mathrm{cm}$ intervals from the quarter-sawn lumber ( $5 \mathrm{~cm}$ thick). The strain of each segmented wood samples was measured using a $500 \mathrm{~N}$ horizontal-universal testing machine, connected to a strain meter with a computer interface.

\section{Analysis of data}

The analysis on wood maturity assumed that fibre length is shortest at the pith, increases gradually outward, and then stabilises at a certain point (Ohbayashi \& Shiokura 1990, Kojima et al. 2009). To assess the results objectively, the relationship between fibre length $(\mathrm{y} \mathrm{mm})$ and the distance from the pith $(\mathrm{x} \mathrm{cm})$ was approximated by the following exponential function (Kojima et al. 2009):

$$
y(x ; b)=-\left(y_{\infty}-y_{0}\right) \exp ^{-b(|x|-1)}+y_{\infty}
$$

where, $\mathrm{y}_{\infty}=$ fibre length in the mature wood region, and $\mathrm{y}_{0}=$ fibre length measured 1 $\mathrm{cm}$ from the pith. On the basis of $\mathrm{DBH}$, the test trees were arbitrarily divided into small, medium, and large diameter classes for each species. The $\mathrm{y}_{\infty}$ value was the average fibre length value at the outermost point in the large-diameter class tree, whereas $y_{0}$ was the average value $1 \mathrm{~cm}$ from the pith in all trees tested. The b-value $\left(\mathrm{cm}^{-1}\right)$ was obtained from the radial distribution of fibre length in each tested tree by the least-squares method using equation 1 .

In the determination of juvenile, transition and mature wood zones, the north and south sides of each tree sample was used.

(1) Juvenile wood zone $\left(0<\mathrm{x}<\mathrm{x}_{\mathrm{j}}\right)$

$$
\frac{100\left(y\left(x_{j}+1\right)-y\left(x_{j}\right)\right)}{y\left(x_{j}\right)}=1(\%)
$$

From equation $1, \mathrm{x}_{\mathrm{j}}$ can be solved as in equation 3

$$
\mathrm{x}_{\mathrm{j}}=\frac{\ln \left(100\left(\mathrm{y}_{\infty}-\mathrm{y}_{0}\right)\left(1.01-\exp ^{-\mathrm{b}}\right) / \mathrm{y}_{\infty}\right)}{\mathrm{b}}+1
$$

where, $\mathrm{x}_{\mathrm{j}}=$ distance from the pith at the $1 \%$ expansion point, where the expansion rate of fibre length from $x$ to $x+1(\mathrm{~cm})$ in radius becomes $1 \%$.

(2) Mature wood zone $\left(x_{m}<x\right)$

$$
\frac{100\left(\mathrm{y}\left(\mathrm{x}_{\mathrm{m}}+1\right)-\mathrm{y}\left(\mathrm{x}_{\mathrm{m}}\right)\right)}{\mathrm{y}\left(\mathrm{x}_{\mathrm{m}}\right)}=0.1(\%)
$$

From equation $1, \mathrm{x}_{\mathrm{m}}$ can be solved as

$$
\mathrm{x}_{\mathrm{m}}=\frac{\ln \left(1000\left(\mathrm{y}_{\infty}-\mathrm{y}_{0}\right)\left(1.001-\exp ^{-\mathrm{b}}\right) / \mathrm{y}_{\infty}\right)}{\mathrm{b}}+1
$$


where, $\mathrm{x}_{\mathrm{m}}=$ distance from the pith at the $0.1 \%$ expansion point, where the expansion rate of fibre length from $x$ to $x+1(\mathrm{~cm})$ in radius becomes $0.1 \%$. From this definition, xylem maturation starts at the time when tree radius becomes larger than $x_{m}$.

(3) Transition wood zone $\left(\mathrm{x}_{\mathrm{j}}<\mathrm{x}<\mathrm{x}_{\mathrm{m}}\right)$

In this zone the wood quality changes from the juvenile to mature wood zone. The juvenile zone can be defined as the distance from the pith to the radius at the $0.3 \%$ expansion point, where expansion rate of fibre length from $\mathrm{x}$ to $\mathrm{x}+1(\mathrm{~cm})$ in radius becomes $0.3 \%$.

$$
\frac{100\left(\mathrm{y}\left(\mathrm{x}_{\mathrm{t}}+1\right)-\mathrm{y}\left(\mathrm{x}_{\mathrm{t}}\right)\right)}{\mathrm{y}\left(\mathrm{x}_{\mathrm{t}}\right)}=0.3(\%)
$$

From equation $1, \mathrm{x}_{\mathrm{t}}$ can be solved as

$$
\mathrm{x}_{\mathrm{t}}=\frac{\ln \left(1000\left(\mathrm{y}_{\infty}-\mathrm{y}_{0}\right)\left(1.003-\exp ^{-\mathrm{b}}\right) / 3 \mathrm{y}_{\infty}\right)}{\mathrm{b}}+1
$$

where, $x_{t}=$ boundary diameter, which is the sum of north side and south side of each tree.

Comparing the wood maturation properties, simple linear regression models were used to test the correlation between lateral growth rate and fibre length b-value and tree wood zones. Fibre length, fibre width, vessel length, vessel width, xylem diameter, and MOE between diameter classes were tested using one-way analysis of variance (ANOVA) and Scheffe's method to test the multiple mean comparison using SPSS version 20 .

\section{RESULTS AND DISGUSSION}

\section{Radial distribution pattern}

Fibre length, fibre width, vessel length and vessel width

Radial distribution patterns of xylem maturation properties, namely, fibre length, fibre width, vessel length and vessel width in various diameter classes of the big-leaf mahogany are shown in Figures 3(a-f). Fibre length, vessel length and vessel width exhibited short fibre and vessel length, narrow vessel width from the pith, and gradual increase outward and became more or less stable near the bark. Similar results were observed in
Leucaena leucocephala where fibre length and vessel width showed significant variation from pith to near the bark (Pramod \& Rao 2012), Falcataria moluccana (Kojima et al. 2009) and Antocephalus cadamba (Rahayu et al. 2014). However, the radial distribution pattern of fibre width was overlapped and scattered regardless of diameter class.

Table 3 describes the regression analyses of the relationship between xylem maturation properties. Fibre length was positively correlated with vessel length and width. However, no correlation was detected between fibre length and fibre width and MOE. Quanci (1988) observed similar findings whereby cell length did not contribute to MOE variation in white ash. The result indicates the potential of vessel length and vessel width to be used in identifying boundary distance between juvenile and mature wood. We also considered the relationship between b-value as affected by DBH that showed no significant relationship between fibre length, vessel length and vessel width (Figure 4 ). In this case, the area of juvenile wood zone was uniform, regardless of diameter, showing that xylem maturation depended on diameter. Therefore, this suggests that maturation starts after a certain diameter is reached as described by Kojima et al. (2009).

The relationship between DBH and boundary diameters of selected xylem maturation properties (fibre length, vessel length and vessel width) are shown in Figure 5 and the calculated ANOVA are in Table 4. Using one-way ANOVA, diameter boundaries of the three wood zones (juvenile wood, transition wood and mature wood) were highly significant in fibre length, vessel length and vessel width. Table 5 shows the comparison between the means using Scheffe's test. The fibre length, vessel length, vessel width and xylem density of the juvenile wood zones showed significant differences compared with the transition and mature wood zones. However, no significant difference was observed between transition wood zone and mature wood zone except for fibre length. A negative correlation was observed in fibre length, vessel length and vessel width in terms of their relationship between DBH and the b-value and diameter boundaries of the three wood zones. At diameters 18.08, 17.36, 16.23 and $17.87 \mathrm{~cm}$ respectively, fibre length, vessel 
(a)
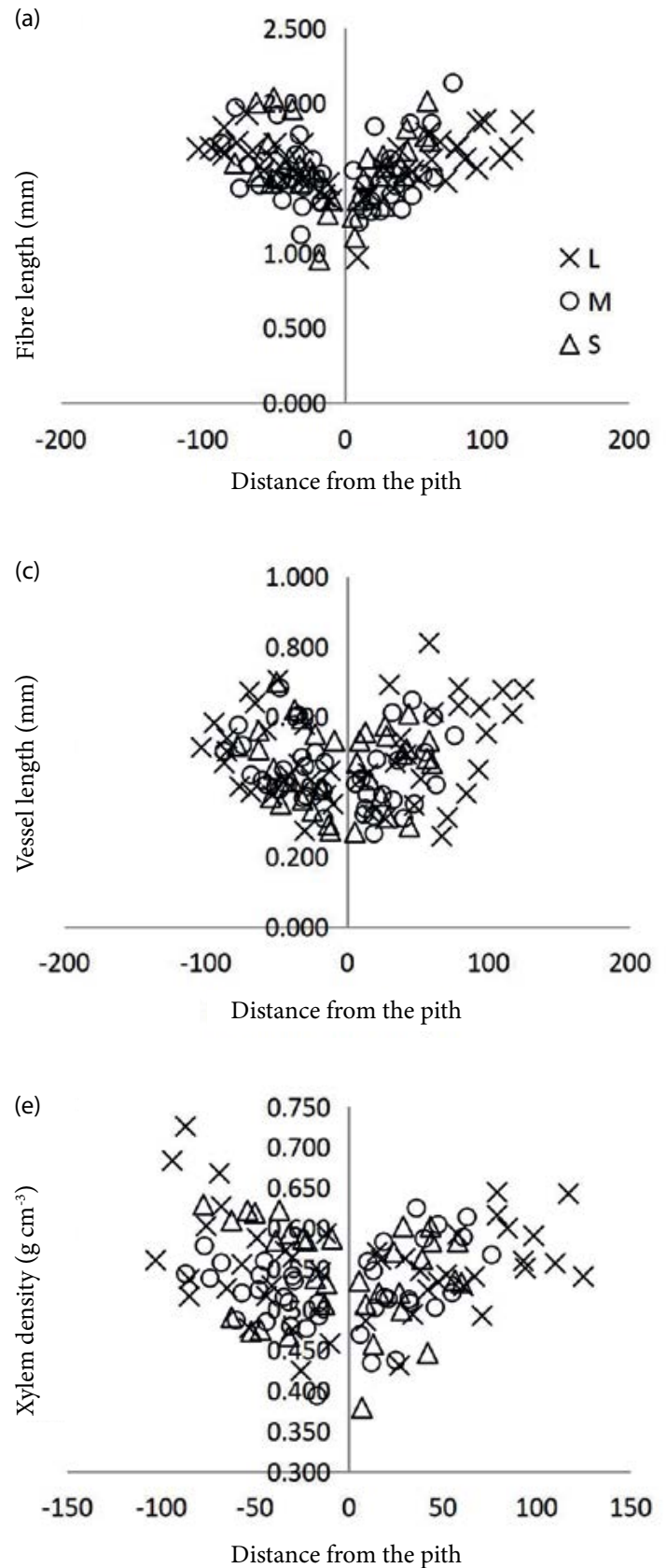

(b)
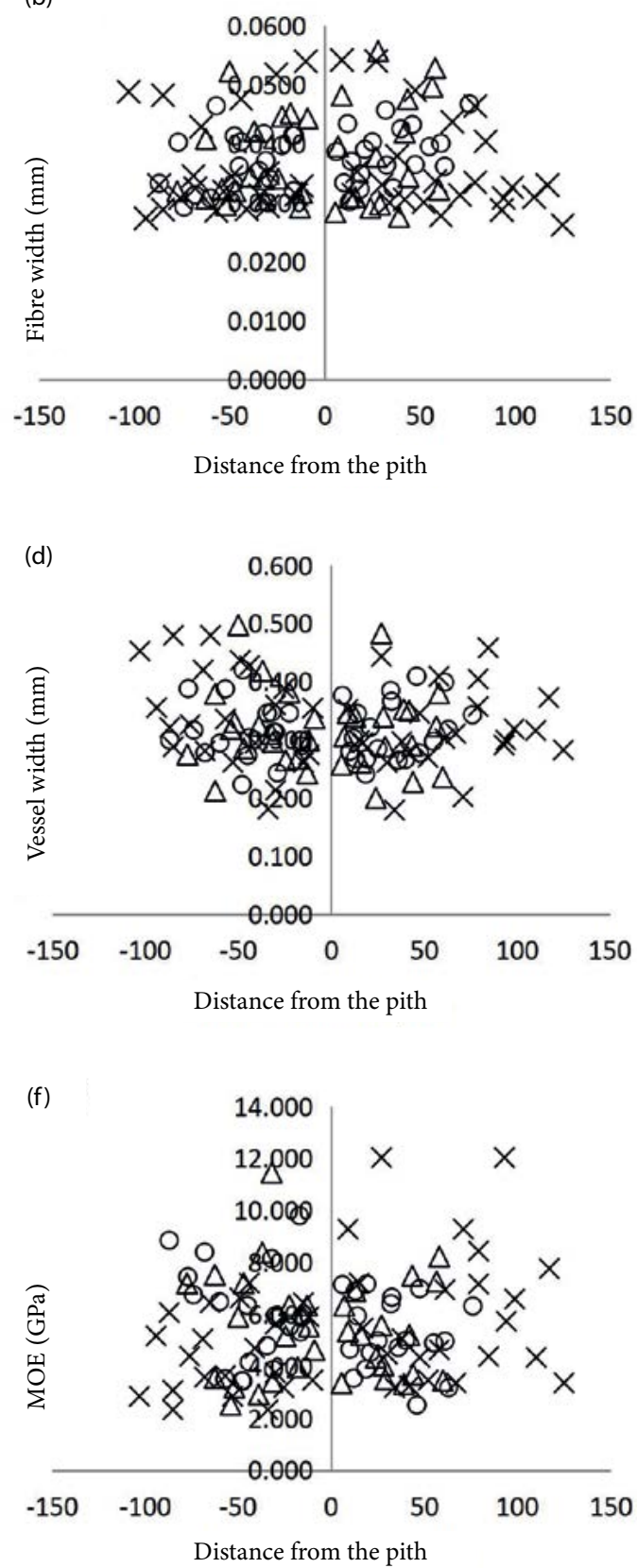

Figure 3 Typical radial distribution pattern of different diameter classes; $(\triangle)$ small diameter trees, $(O)$ medium diameter trees and $(x)$ large diameter trees in different xylem maturation properties

length, vessel width and xylem density can be used to identify xylem maturation boundary.

\section{Xylem density}

Radial distribution of xylem density in various diameter classes is shown in Figure 3. Xylem density was low from the pith, and exhibited gradual increase outward and became more or less stable near the bark. This is similar with the study of Rahayu et al. 2014, in that the density values for 5- and 6-year-old Antocephalus cadamba near the pith are 234 and $297 \mathrm{~kg} \mathrm{~m}^{-3}$ respectively, and near the bark, 573 and $606 \mathrm{~kg}$ $\mathrm{m}^{-3}$ respectively. The xylem density of 5-year-old F. moluccana near the pith was $237 \mathrm{~kg} \mathrm{~m}^{-3}$ and the 6-year-old, $259 \mathrm{~kg} \mathrm{~m}^{-3}$, and the density near the bark was $393 \mathrm{~kg} \mathrm{~m}^{-3}$ for the former and 456 $\mathrm{kg} \mathrm{m}^{-3}$ for the latter. Pinus radiata exhibited an increasing xylem density from pith to bark pattern that tended towards an asymptotic value (Barrios et al. 2017).

The relationship between fibre length and xylem density was positive (Table 3 ). 
Table 3 Correlation coefficients between xylem maturation properties of 8-year-old planted big-leaf mahogany

\begin{tabular}{llccccc}
\hline Variable & & Vessel length & Fibre width & Vessel width & MOE & Xylem density \\
\hline Fibre length & Correlation & $0.565^{* *}$ & 0.076 & $0.420^{* *}$ & -0.025 & $0.469^{* *}$ \\
& $\mathrm{~N}$ & 115 & 115 & 115 & 115 & 115 \\
\multirow{5}{*}{ Vessel length } & Correlation & & 0.087 & $0.483^{* *}$ & 0.066 & $0.290^{* *}$ \\
& $\mathrm{~N}$ & & 115 & 115 & 115 & 115 \\
\multirow{2}{*}{ Fibre width } & Correlation & & & $0.556^{* *}$ & 0.176 & -0.149 \\
& $\mathrm{~N}$ & & 115 & 115 & 115 \\
\multirow{2}{*}{ Vessel width } & Correlation & & & 0.106 & 0.163 \\
& $\mathrm{~N}$ & & & 115 & 115 \\
MOE & Correlation & & & & 0.020 \\
& $\mathrm{~N}$ & & & & 115 \\
\hline
\end{tabular}

**Correlation is significant at the 0.01 level (2-tailed); $\mathrm{MOE}=$ modulus of elasticity

(a)

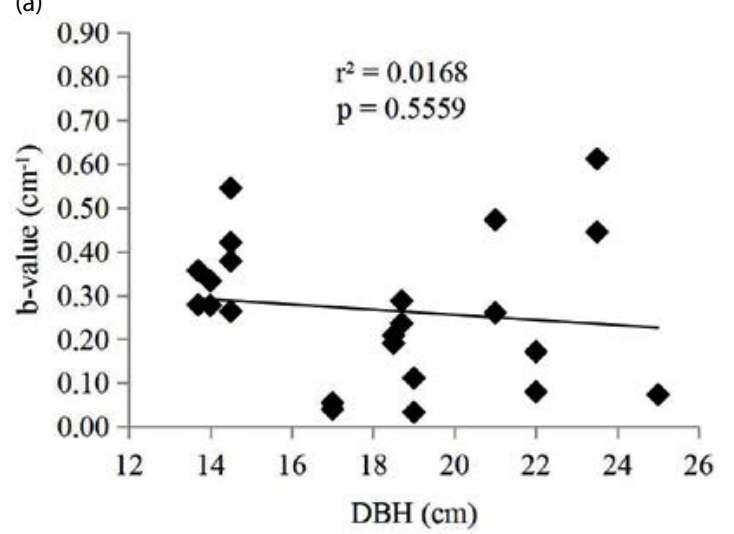

(c)

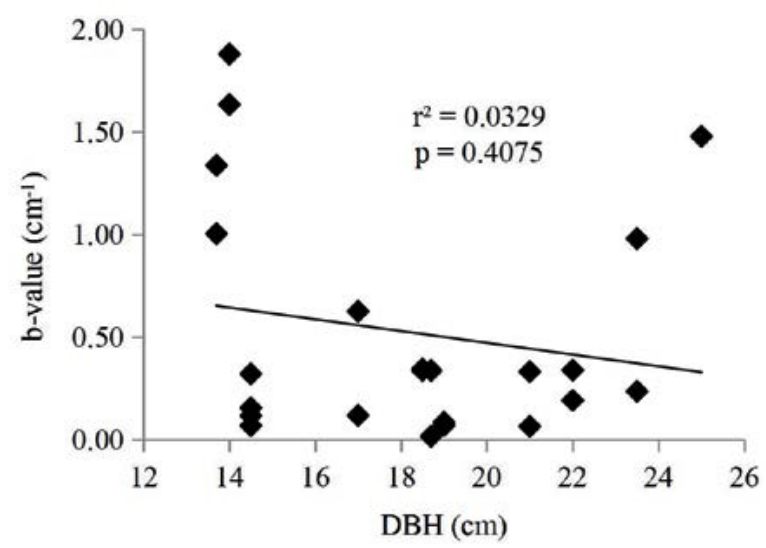

(b)

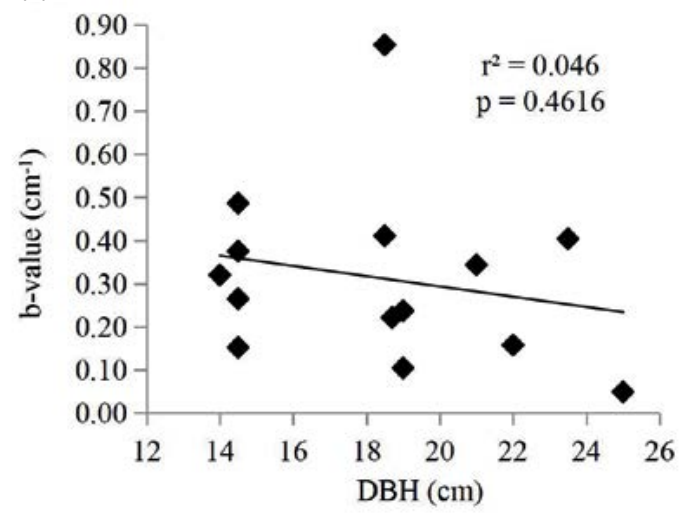

(d)

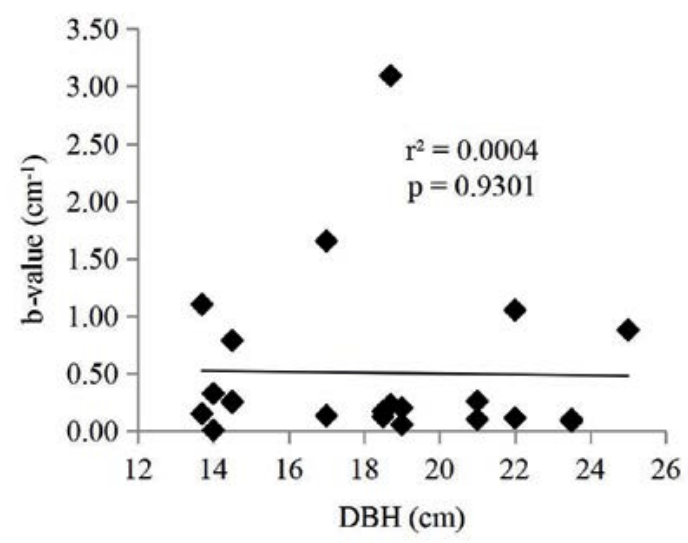

Figure 4 The relationship between $\mathrm{DBH}$ and b-value determined from the radial distribution of different xylem maturation properties; (a) fibre length, (b) vessel length, (c) vessel width, (d) xylem density; $\mathrm{r}^{2}$ represents the contribution ratio, and $\mathrm{p}$ is the probability value 
(a)

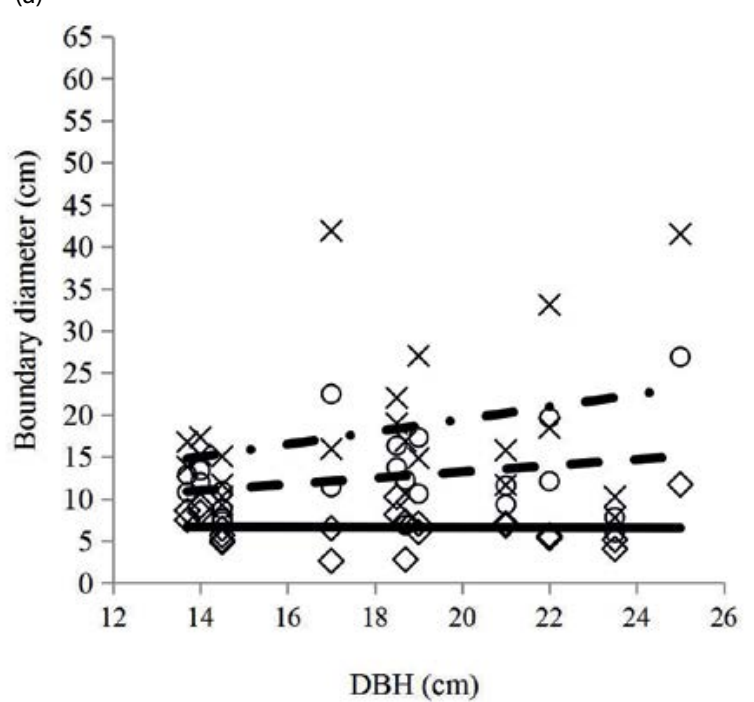

(c)

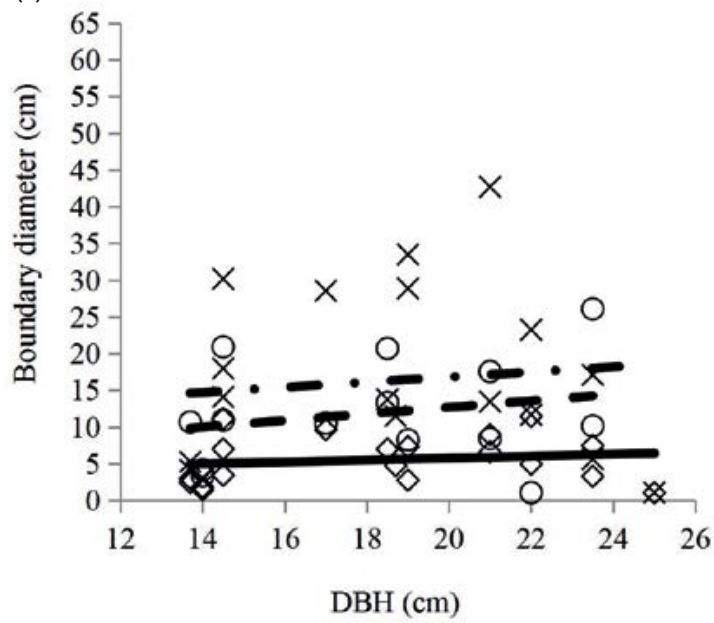

(b)

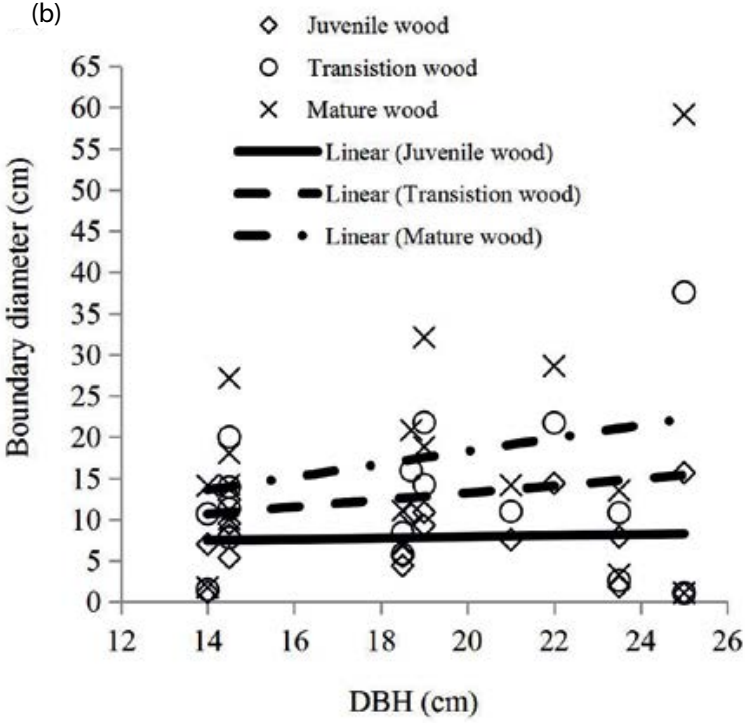

(d)

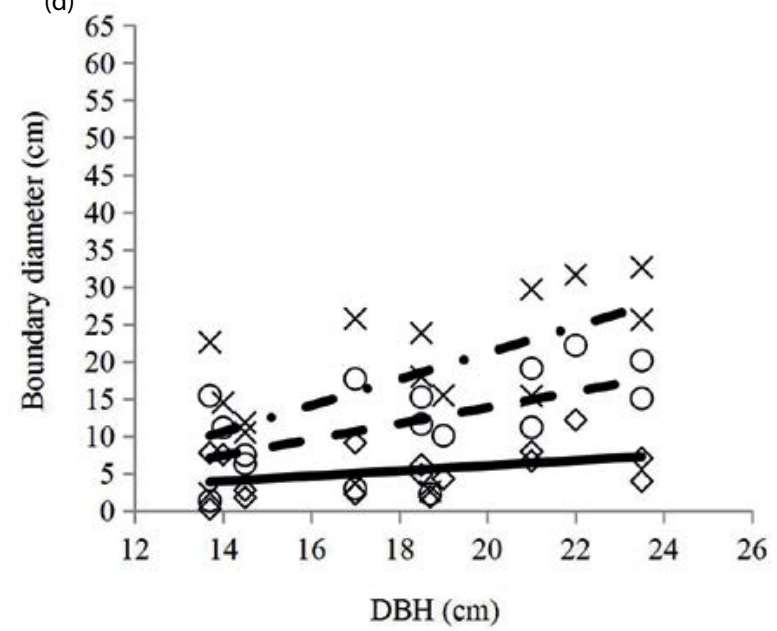

Figure 5 The relationship between diameter boundaries of tree wood zones: $(\diamond)$ juvenile wood, $(O)$ transition wood and $(\times)$ mature wood and averaged DBH of selected xylem maturation property; (a) fibre length, (b) vessel length, (c) vessel width, (d) xylem density.

Table 4 One-way analysis of variance (ANOVA) for the effects of diameter boundaries of three wood zones (juvenile wood, transition wood and mature wood) in selected xylem maturation properties

\begin{tabular}{lcccc}
\hline Source of variation & df & SS & MS & p-value \\
\hline Fibre length & 2 & 1516.65 & 758.32 & 0.0000 \\
Vessel length & 2 & 775.41 & 387.70 & 0.0020 \\
Vessel width & 2 & 1086.17 & 543.08 & 0.0000 \\
Xylem density & 2 & 1241.96 & 620.98 & 0.0000 \\
\hline
\end{tabular}

$\mathrm{SS}=$ sum-of-squares, MS = mean square 
Table 5 Average diameter boundaries of three wood zones of selected xylem maturation properties

\begin{tabular}{lccc}
\hline \multirow{2}{*}{ Xylem maturation property } & \multicolumn{3}{c}{ Wood zone } \\
\cline { 2 - 4 } & Juvenile & Transition & Mature \\
\hline Fibre length & $6.60^{\mathrm{a}}$ & $12.51^{\mathrm{b}} .08^{\mathrm{c}}$ \\
Vessel length & $7.81^{\mathrm{a}}$ & $12.71^{\mathrm{b}}$ & $17.36^{\mathrm{b}}$ \\
Vessel width & $5.54^{\mathrm{a}}$ & $10.89^{\mathrm{b}}$ & $16.23^{\mathrm{b}}$ \\
Xylem density & $5.41^{\mathrm{a}}$ & $11.83^{\mathrm{b}}$ & $17.87^{\mathrm{b}}$ \\
\hline
\end{tabular}

Means followed by the same letters in the same row are not significantly different at $p \leq 0.05$ according to Scheffe's method

Like fibre length, xylem density can be used to identify the boundary distance between juvenile and mature wood. The relationship between b-value and DBH showed no significant results to xylem density, and so this theory was confirmed (Figure 4). From the ANOVA, diameter boundaries of the juvenile, transition and mature wood zones were highly significant in xylem density (Table 4 ). Table 5 shows the comparison between the means using Scheffe's test. Juvenile wood zone of xylem density was significantly different in the transition wood zone and mature wood zone, but no differences were observed between transition and mature wood zones. Xylem density had the same trends as fibre length, vessel length and vessel width in terms of its relationship between DBH and b-value and diameter boundaries of three wood zones.

\section{Modulus of elasticity}

The radial distribution patterns of MOE overlapped with each other and were scattered regardless of diameter as shown in Figure 3. This result contradicts the study of Pinus radiata that exhibited an increasing MOE value from pith to bark that tended towards an asymptotic value (Barrios et al. 2017). The relationship between fibre length and MOE had no correlation as shown in Table 3 . The authors above reported almost similar MOE value $(5.45 \mathrm{GPa})$ from pith to bark regardless of diameter class.

\section{CONGLUSIONS}

Radial distribution patterns exhibited short fibre length and vessel length, narrow vessel width and low xylem density at the pith, and exhibited gradual increases outward and became more or less stable near the bark. However, the radial distribution patterns of fibre width and MOE overlapped each other and were scattered regardless of tree diameter class. The fibre length, vessel length, vessel width and xylem density of the juvenile wood zones showed significant differences compared with the transition and mature wood zones. However, no significant difference was observed between transition wood zone and mature wood zone except for fibre length. A negative correlation was observed in fibre length, vessel length, vessel width and xylem density in terms of their relationship between DBH and b-value, and diameter boundaries of the three wood zones. Therefore, it is important to enhance tree plantation by selecting quality planting materials and having good planting site. Applying appropriate silvicultural practices will help in promoting high lateral growth rate to produce large diameter trees in a shorter period of time in order to promote xylem maturation. At diameters 18.08, 17.36, 16.23 and $17.87 \mathrm{~cm}$ respectively, fibre length, vessel length, vessel width and xylem density can be used to identify xylem maturation boundary.

\section{ACKNOWLEDGEMENTS}

This study was supported by the Nagoya University Asian Satellite Campuses Institute, the Japan International Cooperation Agency and Southeast Asian Regional Center for Graduate Study and Research in Agriculture. Support from the Department of Environment and Natural Resources-Ecosystems Research and Development Bureau (DENR-ERDB) and the Forest and Wetland Research, Development and Extension Center (ERDB-FWRDEC) are gratefully acknowledged. 


\section{REFERENGES}

Abarquez A, Bush D, Ata J, Tolentino El Jr \& Gilbero D. 2015. Early growth and genetic variation of mahogany (Swietenia macrophylla) in progeny test planted in Northern Mindanao, Philippines. Journal of Tropical Forest Science 27: 314-324.

Barrios A, Trincado G \& Watt MS. 2017. Wood properties of juvenile and mature wood of Pinus radiata $\mathrm{D}$. Don trees growing on contrasting sites in Chile. Forest Science 63: 184-191. https://doi. org/10.5849/forsci.2016-060

Bendtsen BA. 1978. Properties of wood from improved and intensively managed trees. Forest Products Journal 28: 61-72.

Cheng Z, Fujiwara S, Ohtani Y \& Sameshima K. 2000. A new method of sample preparation for kenaf bast fiber length analysis with automated fiber length analyzer. Holzforschung 54: 213-218. https://doi. org/10.1515/HF.2000.036

Honjo K, Furukawa I \& SAHri MH. 2005. Radial variation of fiber length increment in Acacia mangium. IAWA Journal 26: 339-352. https://doi. org/10.1163/22941932-90000119

Huang R \& Furukawa I. 2000. Horizontal variations of vessel element length and wood fiber length of two kinds of poplars planted in the desert areas of China. Mokuzai Gakkaishi 46: 495-502.

Kollmann FFP \& Cote JR WA. 1968. Principles of Wood Science and Technology. I. Solid Wood. Springer-Verlag, Berlin, Heidelberg, New York.

Kojima M, Yamamoto H, Marsoem SN et al. 2009. Effects of the lateral growth rate on wood quality of Gmelina arborea from 3.5-, 7- and 12-year-old plantations. Annals of Forest Science 66: 507. https:/ / doi.org/10.1051/forest/2009031

LeE GH \& WANG SY. 1996. A new technique for the demarcation between juvenile and mature wood in Cryptomeria japonica. IAWA Journal 17: 125-131. https://doi.org/10.1163/22941932-90001440

MAEGLIN RR. 1987. Juvenile wood, tension wood and growth stress effect on processing hardwoods. Pp 100-108 in Proceedings of the 15th Annual Symposium of the Hardwood Research Council. 1-12 May 1987, Memphis.

OhBAYASHI H \& Shiokura T. 1990. Wood anatomical characteristics and specific gravity of fast-growing tropical trees species in relation to growth rate. Mokuzai Gakkaishi 36: 889-893.

Pagasa (Philippine Atmospheric, Geophysical and Astronomical Services Administration). 2010. Climate of the Philippines. http:/kidlat.pagasa. dost. gov.ph/cab/statfram.htm

Pramod S \& RaO KS. 2012. Anatomical changes during transition from juvenile to adult wood in branch and main trunk xylem of subabul (Leucaena leucocephala [Lam.] de Wit). Journal of Sustainable Forestry 31: 661-673. https://doi.org/10.1080/105 49811.2012.684300

QuANCI MJ. 1988. Mechanical and anatomical properties of short rotation Douglas-fir and white ash. MSc thesis, Purdue University, West Lafayette.

Rahayu I, Darmawan W, Nugroho N, Nandika D \& Marchal R. 2014. Demarcation point between juvenile and mature wood in segon (Falcataria moluccana) and jabon (Anthocephalus cadamba). Journal of Tropical Forest Science 26: 331-339.

SAIKI H, XU Y \& FuJITA M. 1989. The fibrillar orientation and microscopic measurement of the fibril angles in young tracheid walls of Sugi (Cryptomeria japonica). Mokuzai Gakkaishi 35: 786-792.

Shiokura T. 1982. Extent and differentiation of the juvenile wood zone in coniferous tree trunks. Mokuzai Gakkaishi 28: 85-90.

Sudo S. 1973. Variation in tracheid length in akamatsu (Pinus densiflora Sieb. Et Zucc.). Effects of growth on tracheid length. Mokuzai Gakkaishi 19: 405-412. 